\title{
Kemampuan Literasi Teknologi Siswa Kelas X pada Program Keahlian Multimedia: Analysis \& Deskripsi
}

\author{
Musalina $^{1)} *$, La Tahang ${ }^{2)}{ }_{\text {Erniwati }}{ }^{3)}$ \\ 1)* Mahasiswa Jurusan Pendidikan Fisika, Universitas Halu Oleo, Indonesia \\ ${ }^{2), 3)}$ Jurusan Pendidikan Fisika, Universitas Halu Oleo, Indonesia \\ *Korespondensi Author Email: muslina@gmail.com
}

\begin{abstract}
Abstrak: Penelitian ini bertujuan untuk mengetahui hasil kemampuan literasi teknologi siswa terhadap aspek teknis, aspek kognitif dan aspek sosial. Objek dalam penelitian ini adalah siswa kelas X pada program keahlian multimedia dengan jumlah 100 orang. Penelitian ini menggunakan metode penelitian deskriptif-kuantitatif. Instrumen yang digunakan dalam penelitian ini adalah angket literasi teknologi siswa. Jenis data yang diperoleh adalah data kuantitatif yang diperoleh dari angket kemampuan literasi teknologi siswa. Prosedur analisis data dalam penelitian ini adalah: (1) menghitung skor total dari angket untuk masing-masing siswa; (2) menentukan nilai kemampuan literasi teknologi siswa untuk setiap indikator; dan (3) mengkategorikan kemampuan literasi teknologi siswa berdasarkan aspek teknis, kognitif dan sosial. Hasil kemampuan literasi teknologi siswa kelas X program keahlian multimedia di SMKN 4 Kendari untuk per aspek yaitu pada aspek teknis yaitu 84,75\% berada pada kategori baik pada aspek kognitif yaitu 71,06 \% berada pada kategori cukup baik. dan pada aspek sosial yaitu 86, $31 \%$ berada pada kategori sangat baik. Dengan demikian dapat disimpulkan bahwa kemampuan literasi teknologi siswa khususnya pada aspek kognitif masih rendah dan perlu ditingkatkan agar ke depan dapat bersaing dalam perkembangan teknologi. Oleh karena itu, bagi peneliti selanjutnya disarankan agar fokus pada aspek kognitif.
\end{abstract}

Kata Kunci: Literasi; Pengetahuan Kognitif

\begin{abstract}
This study aims to determine the results of students' technological literacy abilities on technical aspects, cognitive aspects and social aspects. The object in this study was class $X$ students on a multimedia expertise program with 100 people. This research uses descriptive-quantitative research methods. The instrument used in this study was a student technology literacy questionnaire. The type of data obtained is quantitative data obtained from the student's technological literacy abilities questionnaire. Data analysis procedures in this study were: (1) calculating the total score from the questionnaire for each student; (2) determine the value of students' technology literacy abilities for each indicator; and (3) categorizing students' technology literacy abilities based on technical, cognitive and social aspects. The results of the technology literacy ability of the tenth grade students of the multimedia expertise program at SMKN 4 Kendari for each aspect, namely the technical aspects, $84.75 \%$ are in the good category in the cognitive aspect, $71.06 \%$ are in the quite good category. and in the social aspect, 86, 31\% are in the very good category. Thus it can be concluded that students' technological literacy skills, especially in the cognitive aspects are still low and need to be improved so that in the future they can compete in technological development. Therefore, further researchers are advised to focus on cognitive aspects.
\end{abstract}

Keywords: Literacy; Cognitive Domain

\section{PENDAHULUAN}

Berkembangnya teknologi dalam kehidupan, membawa perubahan besar dalam bidang pendidikan untuk menghadapi tantangan global abad ke-21 (Oviyanti, 2016). Memasuki abad ke-21 ini kita dihadapkan pada tuntutan akan pentingnya sumber daya manusia yang berkualitas serta mampu berkompetisi. Sumber daya manusia yang berkualitas yang dihasilkan oleh pendidikan yang berkualitas dapat menjadi kekuatan utama untuk mengatasi masalah- masalah yang dihadapi dalam pendidikan (Cintamulya, 2015).

Pendidikan adalah salah satu kunci kemajuan bangsa, semakin baik kualitas sumber daya manusia maka semakin berkualitas juga bangsa dimata dunia (Kawuri \& Fayanto, 2020). Kualitas pendidikan merupakan pemegang peran penting kemajuan suatu negara, yang sebagian besar ditentukan oleh mutu kegiatan belajar mengajar di 
sekolah (Fatmawati, dkk. 2019). Pemanfaatan teknologi informasi menjadi salah satu cara yang digunakan pemerintah untuk memperbaiki mutu pendidikan Indonesia. Namun, pemanfaatan teknologi informasi yang tidak tepat menjadi salah satu penyebab kurangnya minat baca peserta didik saat ini.

Salah satu hal yang paling berpengaruh dalam dunia pendidikan adalah tingkat kemampuan dan minat membaca peserta didik, artinya bahwa dalam dunia pendidikan diperlukan sebuah gerakan, gerakan yang dimaksud disini adalah gerakan literasi, salah satu contohnya yaitu literasi teknologi. Literasi teknologi adalah kemampuan untuk menggunakan, memahami, mengatur, dan menilai suatu inovasi yang melibatkan proses dan ilmu pengetahuan untuk memecahkan masalah dan memperluas kemampuan seseorang. Dengan demikian sangat penting untuk memberikan bekal kemampuan literasi teknologi di lingkungan pendidikan utamanya Sekolah Menengah Kejuruan (SMK) sebagai bekal kecakapan siswa (Nasution, 2018)

Sekolah Menengah Kejuruan (SMK) merupakan jenjang sekolah yang mana siswanya diarahkan agar mempunyai keahlian tertentu, sehingga jurusan yang diberikan berbeda dengan jurusan di Sekolah Menengah Atas (SMA). Jurusan yang diberikan di SMK sangat bervariasi salah satu diantaranya adalah jurusan Multimedia. Multimedia merupakan perpaduan antara berbagai media (format file) yang berupa teks, gambar, grafik, sound, animasi, video, interaksi dan lain-lain yang telah dikemas menjadi file digital (komputerisasi) digunakan untuk menyampaikan atau menghantarkan pesan kepada publik.

Gambaran kemampuan mengenai literasi teknologi dapat dilihat pada penelitian Farihah (2018) pengaruh literasi teknologi informasi dan komunikasi terhadap kemampuan berpikir kritis siswa kelas $\mathrm{X}$ manajemen pemasaran 1 SMK Pasundan 4 Bandung adalah sebesar 45.9\%. Literasi dengan memanfaatkan teknologi informasi dan komunikasi cukup berkontibusi terhadap kemampuan berpikir kritis siswa. Sekolah, diharapkan dapat meningkatkan kualitas pengajaran dengan memanfaatkan teknologi informasi dan komunikasi, agar dapat membantu meningkatkan kemampuan berpikir kritis terhadap peserta didiknya. Siswa, harus bisa menyadari bahwa dengan melakukan literasi TIK dapat meningkatkan kemampuannya dalam berpikir kritis. Rahmala (2018) menyatakan bahwa siswa SMK Negeri 4 Malang sudah cukup mampu mengaplikasikan literasi informasi dalam proses pembelajaran walaupun terdapat beberapa siswa yang tidak menerapkan seluruh langkah kemampuan literasi yang ada.

Berdasarkan hasil observasi yang telah dilakukan disalah satu sekolah menengah kejuruan yang ada di Kendari, yaitu di SMK Negeri 4 Kendari, diperoleh hasil observasi dimana sekolah ini sudah memiliki fasilitas teknologi informasi dan komunikasi contohnya program keahlian yang berkaitan dengan teknologi yaitu teknik komputer dan jaringan, multimedia dan rekayasa perangkat lunak semua itu jurusan di SMK Negeri 4 Kendari yang bregerak di bidang teknologi. Namun kemampuan literasi teknologi siswa di SMK Negeri 4 Kendari belum diketahui apakah tergolong tinggi atau rendah. Hal ini dikarenakan pada sekolah tersebut belum pernah dilakukan tes kemampuan literasi teknologi. Sehingga berdasarkan hasil observasi di SMK Negeri 4 Kendari dan pentingnya literasi teknologi bagi setiap siswa, maka penulis tertarik melakukan penelitian yang berjudul Kemampuan literasi teknologi siswa kelas X pada program keahlian multimedia di SMK Negeri 4 Kendari. Permalasahan yang dikaji pada: 1. Bagaimana gambaran kemampuan literasi teknologi siswa pada aspek teknis kelas X SMKN 4 Kendari program keahlian multimedia?, 2. Bagaimana gambaran kemampuan literasi teknologi siswa pada aspek kognitif kelas X SMKN 4 Kendari program keahlian multimedia?, 3.Bagaimana gambaran kemampuan literasi teknologi siswa pada aspek sosial kelas X SMKN 4 program keahlian multimedia?. Tujuan dari kajian ini adalah menganalisis kemampuan literasi teknologi siswa kelas X pada program keahlian mutimedia.

\section{METODE}

Jenis penelitian ini adalah penelitian deskriptif dengan pendekatan kuantitatif.. Objek dari penelitian ini adalah seluruh kelas $\mathrm{X}$ program keahlian multimedia yang terdaftar di semester genap di SMKN 4 Kendari tahun ajaran 2018/2019 yang disajikan pada Tabel 1. 
Tabel 1. Objek penelitian SMKN 4 Kendari kelas X program keahlian multimedia

\begin{tabular}{ccc}
\hline No. & Kelas & Julmlah Siswa \\
\hline 1 & X MMA & 35 \\
2 & X MMB & 35 \\
3 & X MMC & 30 \\
\hline
\end{tabular}

Teknik pengumpulan data dari penelitian ini menggunakan data primer yang di kumpulkan dengan menggunakan kuesioner (angket). Yang dimaksud dengan data primer adalah data yang diperoleh secara langsung dari objek penelitian melalui hasil kuesioner literasi teknologi siswa SMKN 4 Kendari program keahlian multimedia. Sugiyono (2018) mengatakan bahwa kuesioner merupakan teknik pengumpulan data yang dilakukan dengan cara memberi seperangkat pertanyaan atau pernyataan tertulis kepada responden untuk dijawabnya. Angket literasi teknologi ini diambil dari penelitian Kurnia yang sudah divalidasi. Rincian angket literasi teknologi pada penelitian ini berjumlah 22 pernyataan diantaranya yaitu 7 aspek teknis, 7 pernyataan aspek kognitif dan 8 pernyataan aspek sosial. Pemetaan angket literasi teknologi dapat dilihat dalam Tabel berikut;

Tabel 2. Pemetaan angket literasi teknologi

\begin{tabular}{cll}
\hline Kelas & Aspek Literasi Teknologi & Nomor Pernyataan \\
\hline \multirow{3}{*}{$\mathrm{X}$} & Aspek Teknis & $1,2,3,4,5,6$ dan 7. \\
\cline { 2 - 3 } & Aspek Kognitif & $8,9,10,11,12,13$, dan 14. \\
\cline { 2 - 3 } & Aspek Sosial & $15,16,17,18,19,20,21$ dan 22. \\
\hline
\end{tabular}

Prosedur penelitian terdiri dari Penelitian ini dilakukan dalam tiga tahapan, yakni tahap persiapan, tahap pelaksanaan dan tahap akhir.. Teknik analisis data yang digunakan Data yang diperoleh dalam penelitian merupakan data kuantitatif, dengan menggunakan teknik analisis data stastistik deskriptif. Analisis deskriptif merupakan suatu analisis stastistik

$$
N P=\frac{R}{S M} \times 100 \%
$$

\section{Dengan,}

$N P=$ Nilai kemampuan literasi teknologi,

$R=$ Jumlah skor soal yang dijawab responden,

$S M=$ Skor maksimal dari tes yang digunakan untuk menganalisis data dengan cara mendeskripsikan atau menggambarkan data yang telah terkumpul sebagaimana adanya tanpa bermaksud membuat kesimpulan yang berlaku untuk umum atau generalisasi. Untuk menghitung skor kemampuan literasi teknologi siswa dapat digunakan persamaan berikut;

Tabel 3. Kriteria interpretasi skor literasi teknologi

\begin{tabular}{cc} 
Interval Kriteria & Kriteria \\
\hline $86 \%-100 \%$ & Sangat baik \\
$72 \%-85 \%$ & Baik \\
$58 \%-71 \%$ & Cukup \\
$43 \%-57 \%$ & Rendah \\
$\leq 43$ & Sangat Rendah \\
\hline
\end{tabular}




\section{HASIL PENELITIAN DAN PEMBAHASAN}

Hasil penelitian kemampuan literasi teknologi siswa pada program keahlian multimedia dengan sekolah yang berada di Kota Kendari yang dijabarkan dalam 3 aspek yaitu apsek tekniks, aspek kognitif, dan aspek social. Untuk aspek teknis pada indikator menemukan informasi melalui teknologi informasi dan komunikasi dapat dilihat pada Tabel 4.

Tabel 4. Hasil kemampuan literasi teknologi siswa kelas X program keahlian multimedia pada aspek teknis indikator menemukan

\begin{tabular}{|c|c|c|c|c|c|c|c|c|}
\hline \multirow[b]{2}{*}{ No } & \multirow[b]{2}{*}{ Pertanyaan } & \multicolumn{4}{|c|}{ Frekuensi Jawaban } & \multirow[b]{2}{*}{$\begin{array}{l}\text { Jumlah } \\
\text { Skor }\end{array}$} & \multirow[b]{2}{*}{$(\%)$} & \multirow[b]{2}{*}{ Kategori } \\
\hline & & $\mathbf{S M}$ & $\mathbf{M}$ & $\begin{array}{l}\mathbf{T} \\
\mathbf{M} \\
\end{array}$ & STM & & & \\
\hline 1. & $\begin{array}{l}\text { Saya mampu mengoperasikan } \\
\text { komputer dengan sangat baik }\end{array}$ & 45 & 40 & 14 & 1 & 329 & 82,5 & Baik \\
\hline 2. & $\begin{array}{l}\text { Saya mampu memanfaatkan } \\
\text { internet. }\end{array}$ & 69 & 28 & 3 & 0 & 366 & 91,5 & Sangat Baik \\
\hline 3. & $\begin{array}{l}\text { Saya mampu menggunakan } \\
\text { Google, Yahoo, dan Bing untuk } \\
\text { mencari tugas- tugas sekolah }\end{array}$ & 55 & 38 & 14 & 3 & 345 & 86,25 & Sangat Baik \\
\hline 4. & $\begin{array}{l}\text { saya memiliki akses ke perangkat } \\
\text { komputasi mobile seperti ponsel } \\
3 \mathrm{G} \text { atau iPhone/Android }\end{array}$ & 61 & 20 & 14 & 4 & 339 & 84 & Baik \\
\hline 5. & $\begin{array}{l}\text { Saya mampu mengakses Vidio } \\
\text { Digital dengan menggunakan } \\
\text { Adobe Premer, Movie Maker, } \\
\text { atau iMovie }\end{array}$ & 20 & 39 & 36 & 5 & 274 & 68,5 & Cukup Baik \\
\hline 6. & $\begin{array}{l}\text { saya sering mengunjungi dunia } \\
\text { maya seperti (Facebook, Twitter, } \\
\text { Path, Youtube, dan lain-lain) }\end{array}$ & 69 & 26 & 4 & 1 & 363 & 90,75 & Sangat Baik \\
\hline 7. & $\begin{array}{l}\text { Ketika saya mengakses internet } \\
\text { saya dapat menemukan informasi } \\
\text { yang sesuai untuk menyelesaikan } \\
\text { tugas. }\end{array}$ & 66 & 28 & 3 & 3 & 357 & 89,25 & Sangat Baik \\
\hline & Total & 385 & 219 & 88 & 17 & 2373 & 84,75 & Baik \\
\hline
\end{tabular}

Berdasarkan hasil analisis pada Tabel 4. menunjukkan bahwa aspek teknis SMKN 4 Kendari kelas X program keahlian multimedia pada indikator menemukan yang paling banyak menjawab mampu dengan persentase $82,5 \%$, dengan frekuensi jawaban 40 orang berada pada kategori baik. Yang paling banyak menjawab tidak mampu dengan persentase $68,5 \%$ dengan frekuensi jawaban 36 orang berada pada kategori cukup baik. Tidak mampu disini yaitu siswa belum mampu mengakses Vidio Digital dengan menggunakan Adobe Premer, dan Movie Maker, Walaupun demikian, ada juga beberapa siswa yang sudah menjawab sangat mampu dengan aspek ini. Artinya bahwa mereka sudah mampu menggunakan komputer, jaringan internet dan lain-lain.

Aspek kognitif pada indikator mengevaluasi dan membuat hasil kemampuan literasi teknologi siswa dalam menggunakan teknologi informasi dan komunikasi dapat dilihat pada Tabel 5 dan Tabel 6 
Tabel 5. Hasil kemampuan literasi teknologi siswa kelas X pada aspek kognitif indikator mengevaluasi

\begin{tabular}{|c|c|c|c|c|c|c|c|c|}
\hline \multirow[b]{2}{*}{ No. } & \multirow[b]{2}{*}{ Pertanyaan } & \multicolumn{4}{|c|}{ Frekuensi Jawaban } & \multirow[b]{2}{*}{$\begin{array}{l}\text { Jumlah } \\
\text { Skor }\end{array}$} & \multirow[b]{2}{*}{$(\%)$} & \multirow[b]{2}{*}{ Kategor } \\
\hline & & SM & $\mathbf{M}$ & $\begin{array}{l}\mathbf{T} \\
\mathbf{M}\end{array}$ & STM & & & \\
\hline 8 & $\begin{array}{l}\text { Melalui internet saya dapat } \\
\text { mencari sumber-sumber informasi } \\
\text { yang valid. }\end{array}$ & 30 & 36 & 14 & 20 & 276 & 69 & $\begin{array}{l}\text { Cukup } \\
\text { Baik }\end{array}$ \\
\hline 9 & $\begin{array}{l}\text { Melalui internet saya bisa mencari } \\
\text { tugas-tugas sekolah. }\end{array}$ & 40 & 24 & 21 & 15 & 289 & 72,25 & Baik \\
\hline & Total & 70 & 60 & 35 & 35 & 569 & 70,62 & $\begin{array}{c}\text { Cukup } \\
\text { Baik }\end{array}$ \\
\hline
\end{tabular}

*catatan: $\mathrm{SM}=$ sangat mampu dengan skor 4; $\mathrm{M}=$ mampu dengan skor 3; TM = tidak mampu dengan skor 2; $\mathrm{STM}=$ sangat tidak mampu dengan skor 1

Tabel 6. Hasil kemampuan literasi teknologi siswa kelas X pada aspek kognitif indikator membuat

\begin{tabular}{|c|c|c|c|c|c|c|c|c|}
\hline \multirow{2}{*}{ No } & \multirow{2}{*}{ Pertanyaan } & \multicolumn{4}{|c|}{ Frekuensi Jawaban } & \multirow{2}{*}{$\begin{array}{c}\text { Jumlah } \\
\text { Skor }\end{array}$} & \multirow{2}{*}{$(\%)$} & \multirow{2}{*}{$\begin{array}{c}\text { Kategor } \\
\text { i }\end{array}$} \\
\hline & & SM & $\mathbf{M}$ & TM & STM & & & \\
\hline 10 & $\begin{array}{l}\text { saya mampu mengerjakan tugas } \\
\text { dengan menggunakan Microsoft Word, } \\
\text { Open Office Writer, dll. }\end{array}$ & 40 & 38 & 10 & 12 & 306 & 76,5 & Baik \\
\hline 11. & $\begin{array}{l}\text { Saya mampu membuat tugas } \\
\text { presentasi dengan menggunakan } \\
\text { aplikasi MS Power Point, Open Office } \\
\text { Impress. }\end{array}$ & 33 & 30 & 22 & 15 & 281 & $\begin{array}{c}70,2 \\
5\end{array}$ & $\begin{array}{c}\text { Cukup } \\
\text { Baik }\end{array}$ \\
\hline 12. & $\begin{array}{l}\text { saya mampu membuat grafis dengan } \\
\text { mengguanakan aplikasi Paint, Adobe } \\
\text { Photoshop, Paint Shop Pro, dll }\end{array}$ & 20 & 36 & 33 & 12 & 266 & 66,5 & $\begin{array}{c}\text { Cukup } \\
\text { Baik }\end{array}$ \\
\hline 13. & $\begin{array}{l}\text { Saya mampu membuat Spredsheet } \\
\text { dengan menggunakan aplikasi MS } \\
\text { Excel, Open Office Calc }\end{array}$ & 23 & 34 & 38 & 5 & 275 & $\begin{array}{c}68,7 \\
5\end{array}$ & $\begin{array}{c}\text { Cukup } \\
\text { Baik }\end{array}$ \\
\hline 14. & $\begin{array}{l}\text { Saya mampu membuat Perekaman } \\
\text { Gambar Digital dengan menggunakan } \\
\text { aplikasi Kamera digital, dan Scanner }\end{array}$ & 34 & 37 & 26 & 3 & 302 & 75,5 & Baik \\
\hline & Total & 150 & 175 & 129 & 47 & 1430 & 71,5 & $\begin{array}{c}\text { Cukup } \\
\text { Baik }\end{array}$ \\
\hline
\end{tabular}

Hasil penelitian kemampuan literasi teknologi siswa SMKN 4 Kendari kelas $\mathrm{X}$ program keahlian Multimedia pada tabel 4.2. menunjukkan bahwa aspek kognitif pada indikator mengevaluasi yang paling banyak menjawab mampu dengan persentase $69 \%$ dengan frekuensi jawaban 36 orang berada pada kategori cukup baik. Artinya bahwa rata-rata siswa pada aspek ini belum mampu mencari sumber-sumber informasi yang valid untuk menyelesaikan tugas sekolah. Dan yang paling banyak menjawab sangat mampu dengan persentase $71,25 \%$ dengan frekuensi jawaban 40 orang berada pada kategori baik. Sedangkan untuk indikator membuat dapat dilihat pada tabel 4.3. menunjukkan bahwa yang paling sedikit menjawab tidak mampu dengan persentase $70,25 \%$, $66,5 \%$ dan 68,75 \% dengan frekuensi jawaban 33, 20 dan 23 orang berada pada kategori yang sama yaitu kategori cukup baik. Rata-rata pada indikator ini siswa belum mampu membuat tugas persentase dengan menggunakan Microsoft power point, membuat grafis dengan menggunakan aplikasi paint, adobe photoshop dan membuat spredsheet dengan menggunakan aplikasi Microsoft excel. Hal ini kemungkinan disebabkan oleh kesadaran yang dimiliki siswa terhadap kemampuannya yang kurang memadai terhadap penggunaan teknologi dan kurangnya kesadaran para siswa tentang pentingnya teknologi sehingga para siswa enggan untuk ingin tahu dan belajar tentang teknologi.

Aspek sosial pada indikator mengkomunikasikan hasil kemampuan literasi teknologi siswa terhadap penggunaan teknologi dapat dilihat pada Tabel 7 . 
Tabel 7. Hasil Kemampuan Literasi Teknologi Siswa Kelas X Pada Aspek Sosial Indikator Mengkomunikasikan

\begin{tabular}{|c|c|c|c|c|c|c|}
\hline \multirow[t]{2}{*}{ No } & \multirow[t]{2}{*}{ Pertanyaan } & \multicolumn{2}{|c|}{$\begin{array}{c}\text { Frekuensi } \\
\text { Jawaban }\end{array}$} & \multirow{2}{*}{$\begin{array}{c}\text { Jumlah } \\
\text { Skor }\end{array}$} & \multirow[t]{2}{*}{$(\%)$} & \multirow[t]{2}{*}{ Kategori } \\
\hline & & Ya & Tidak & & & \\
\hline 15. & $\begin{array}{l}\text { Apakah dalam pemanfaatan teknologi anda } \\
\text { melakukan copy paste }\end{array}$ & 66 & 34 & 166 & 83 & Baik \\
\hline 16. & $\begin{array}{l}\text { Apakah media sosial yang anda gunakan untuk } \\
\text { shering materi belajar }\end{array}$ & 89 & 11 & 189 & 95,5 & $\begin{array}{l}\text { Sangat } \\
\text { Baik }\end{array}$ \\
\hline 17. & $\begin{array}{l}\text { Apakah dalam melakukan komunikasi anda } \\
\text { menggunakan Email, Chatting atau SMS }\end{array}$ & 85 & 15 & 185 & 92,5 & $\begin{array}{l}\text { Sangat } \\
\text { Baik }\end{array}$ \\
\hline 18. & $\begin{array}{l}\text { Apakah media sosial yang anda gunakan untuk } \\
\text { melakukan diskusi pembelajaran }\end{array}$ & 85 & 15 & 185 & 92,5 & $\begin{array}{l}\text { Sangat } \\
\text { Baik }\end{array}$ \\
\hline 19. & $\begin{array}{l}\text { Anda sering menggunakan media sosial, apakah } \\
\text { berpengaruh pada waktu belajar }\end{array}$ & 55 & 45 & 155 & 77,5 & Baik \\
\hline 20. & $\begin{array}{l}\text { Apakah media sosial yang anda gunakan untuk } \\
\text { kuis }\end{array}$ & 59 & 41 & 159 & 79,5 & Baik \\
\hline 21. & $\begin{array}{l}\text { Apakah media sosial yang anda gunakan untuk } \\
\text { konsultasi dengan guru }\end{array}$ & 70 & 30 & 170 & 85 & Baik \\
\hline 22. & $\begin{array}{l}\text { Anda sering menggunakan media sosial, apakah } \\
\text { membuat anda ketagihan }\end{array}$ & 72 & 28 & 172 & 86 & $\begin{array}{l}\text { Sangat } \\
\text { Baik }\end{array}$ \\
\hline & Total & 581 & 219 & 1381 & 86,31 & $\begin{array}{c}\text { Sangat } \\
\text { Baik }\end{array}$ \\
\hline
\end{tabular}

*catatan: $\mathrm{SM}=$ sangat mampu dengan skor 4; $\mathrm{M}$ = mampu dengan skor 3; TM = tidak mampu dengan skor 2; $\mathrm{STM}=$ sangat tidak mampu dengan skor 1

Berdasarkan hasil analisis pada Tabel 7 menunjukkan bahwa aspek sosial SMKN 4 Kendari kelas X program keahlian multimedia pada indikator mengkomunikasikan yang paling banyak menjawab sangat mampu dengan persentase lebih dari $90 \%$ berada pada kategori yang sama yaitu kategori sangat baik. Artinya bahwa siswa disini sudah sangat baik dalam menyikapi pemanfaatan teknologi misalnya shering materi belajar, memanfaatkan media sosial dalam hal melakukan komunikasi antar teman, sebagai konsultasi dengan guru dan lain-lain. Namun ada beberapa siswa yang mengatakan bahwa dalam menggunakan media sosial dapat berpengaruh terhadap waktu belajar mereka.. Sedangkan untuk Hasil kemampuan literasi teknologi siswa untuk setiap indikator dapat dilihat pada Tabel 8 .

Tabel 8. Hasil kemampuan literasi teknologi siswa kelas x pada setiap indikator

\begin{tabular}{clcc}
\hline $\begin{array}{c}\text { Aspek Literasi } \\
\text { Teknologi }\end{array}$ & \multicolumn{1}{c}{ Indikator } & $\begin{array}{c}\text { Persentase } \\
(\boldsymbol{\%})\end{array}$ & Kategori \\
\hline Aspek Teknis & Menemukan & 85,75 & Baik \\
Aspek Kognitif & Mengevaluasi & 70,62 & Cukup Baik \\
& Membuat & 71,5 & Cukup Baik \\
Aspek Sosial & Mengkomunikasikan & 86,31 & Sangat Baik \\
\hline
\end{tabular}

Berdasarkan Tabel 8 terlihat bahwa pada setiap aspek literasi teknologi yang didalamnya mencakup aspek teknik, aspek kognitif, dan aspek social berada pada kategori baik-sangat baik. Hal ini menunjukkan bahwa kemampuan literasi teknologi siswa kelas $\mathrm{X}$ kelas multimediamenunjukkan perilakuk literasi teknologi yang memadai. Hasil penelitian literasi teknologi siswa SMKN 4 Kendari kelas $\mathrm{X}$ program keahlian Multimedia pada tabel 4.5. dan gambar 1. menunjukan bahwa aspek teknis pada indikator menemukan berada pada kategori baik dengan persentase $84,75 \%$. Aspek kognitif indikator mengevaluasi dan membuat berada pada kategori yang sama yaitu kategori kurang baik berada pada persentase $70,62 \%$ dan $71,5 \%$ untuk keseluruhan kemampuan literasi teknologi siswa pada aspek 
kognitif dapat dilihat pada gambar 1 menunjukkan bahwa aspek kognitif berada pada kategori kurang baik dengan persentase $71,06 \%$. Sedangkan aspek sosial berada pada kategori sangat baik dengan persentase $86,31 \%$. TIK memegang peranan penting dalam segala bidang seperti bidang ekonomi, pendidikan, sosial dan budaya.

Dari beberapa literatu menuntukkan bahwa kemampuan literasi sangat menunjang produktivitas siswa dalam belajarr. Peran literasi dapat megubah perilaku siswa mulai dari aspek kognitif sampai aspek teknisi. Beberapa kajian yang telah dilakukan, khusunya menganalisis siswa di Sulawesi Tenggara menujukkan perilaku literasi yang berbeda ber-beda mulai dari literasi. Erniwati dkk. (2020) dalam studi melaporkan bahwa bahwa rata-rata kemampuan literasi secara menyeluruh memperoleh nilai presentase 50,85\% dengan kategori kemampuan rendah. Dimana pada aspek konten peserta didik kelas X di SMAN 1 Kendari memperoleh nilai presentase $61,43 \%$ dengan kategori cukup. Kemudian untuk kemampuan literasi peserta didik pada aspek proses memperoleh nilai presentase $45,81 \%$ dengan kategori rendah. Sedangkan untuk kemampuan literasi peserta didik pada aspek konteks memperoleh nilai presentase 45,32\% dengan kategori rendah. Sedangkan pada kajian ini aspek literasi sains teknologi berada pada kategori baiksampai sangat baik. Hal ini kemungkinan besar dipengaruhi oleh kemampuan kognitif siswa yang berbeda-beda pada setiap sekolah dan setiap daerah. Oleh karena itu, sangat penting untuk melatih siswa khusunya dalam proses literas baik literasi sains ataupun literasi teknologi guna melatih siswa untuk selalu berpikir, bernalar dan beranalogi.

\section{KESIMPULAN}

Berdasarkan hasil analisis dan deskrpisi diperoleh bahwa $\mathrm{k}$ emampuan literasi teknologi siswa pada aspek teknis nilai tertinggi 4, nilai terendah 1 , reratanya 23,73 dengan persentase $84,75 \%$ berada pada kategori baik. pada aspek kognitif maksimum 4, minimum 1 reratanya 22,76 dengan persentase $81,28 \%$ berada pada kategori baik. Kemampuan literasi teknologi siswa pada aspek sosial nilai maksimum 2, skor minimum 1, reratanya 13,81 dengan persentase 86,31 $\%$ berada pada kategori sangat baik.

Dari temuan yang dipeoleh selama penelitian penulis menyarakan untuk mengenalisis kemampuan literasi teknologi semua semua aspek dengan cakupan wilayah atau sekolah diperluas, sehingga terlihat secara rata-rata kemampuan literasi siswa dalam suatu daerah.

\section{DAFTAR PUSTAKA}

Cintamulya, I. (2015). Peranan Pendidikan dalam Memepersiapkan Sumber Daya Manusia di Era Informasi dan Pengetahuan. Formatif: Jurnal Ilmiah Pendidikan MIPA, 2(2).

Djaali \& Pudji Muljono. (2008). Pengukuran Dalam Bidang Pendidikan. PT. Grasindo: Jakarta

Erniwati, E., Tahang, L., Hunaidah, H., Mongkito, V. H. R., \& Fayanto, S. (2020). Kemampuan Literasi Sains Siswa Sma Di Kota Kendari: Deskripsi \& Analysis. Jurnal Kumparan Fisika, 3(2), 99-108.

Farihah, L. (2018). Pengaruh Literasi Teknologi Informasi Dan Komunikasi Terhadap Kemampuan Berpikir Kritis Siswa Kelas X Manajemen Pemasaran 1 di SMK Pasundan 4 Bandung (Studi Kasus di Kelas X Manajemen Pemasaran 1 SMK Pasundan 4 Bandung Semester Genap Tahun Ajaran 2017/2018) (Doctoral dissertation, FKIP UNPAS).

Fatmawati, F., Sukariasih, L., Fayanto, S., \& Retnawati, H. (2019, May). Investigating the Effectiveness of Inquiry Learning and Direct Learning Models toward Physics Learning. In First International Conference on Progressive Civil Society (ICONPROCS 2019). Atlantis Press.

Kawuri, M. Y. R. T., \& Fayanto, S. (2020). Penerapan Model Discovery Learning Terhadap Keaktifan dan Hasil Belajar Siswa Kelas X MIPA SMAN 1 Piyungan Yogyakarta. Jurnal Penelitian Pendidikan Fisika, 5(1), 1-8.

Nasution, S. H. (2018). Pentingnya Literasi Teknologi Bagi Mahasiswa Calon Guru Matematika. Jurnal Kajian Pembelajaran Matematika, 2(1), 14-18.

Oviyanti, F. (2016). Tantangan pengembangan pendidikan keguruan di era global. Nadwa, 7(2), 267-282.

Rahmala, I. D., Suwignyo, H., \& Kurniawan, T. (2018). Kemampuan Literasi Informasi Pemustaka Berdasarkaninformation Literacy Standars For Student Learning. BIBLIOTIKA: Jurnal Kajian Perpustakaan dan Informasi, 2(1), 6-12.

Sugiyono. (2018). Metode Penelitian Pendidikan Kuantitatif, Kualitatif dan $R \& D$. Alfabeta: Bandung 